\title{
Oxide Terpenes as Human Skin Penetration Enhancers of Haloperidol from Ethanol and Propylene Glycol and Their Modes of Action on Stratum Corneum
}

\author{
Haranath Kumar VAdDI, ${ }^{a}$ Paul Chi-Lui Ho, ${ }^{a}$ Yew Weng Chan, ${ }^{b}$ and Sui Yung CHAN ${ }^{*, a}$ \\ ${ }^{a}$ Department of Pharmacy, National University of Singapore; Singapore 117543, Republic of Singapore: and ${ }^{b}$ Department \\ of Anaesthesiology, Singapore General Hospital; Republic of Singapore.
}

Received September 19, 2002; accepted November 25, 2002

\begin{abstract}
In this study, two terpenes with the same functional group; limonene oxide and pinene oxide were used at $5 \% \mathrm{w} / \mathrm{v}$ concentration in $50 \% \mathrm{v} / \mathrm{v}$ ethanol and $100 \% \mathrm{v} / \mathrm{v}$ propylene glycol (PG) to enhance the in vitro permeation of haloperidol (HP) through the human epidermis (or stratum corneum, SC). The enhancement mechanism of terpenes from both solvents was elucidated with HP-SC binding studies, Fourier transform infrared spectroscopy and differential scanning calorimetry. The enhancement activity of these terpenes was higher in $50 \% \mathrm{v} / \mathrm{v}$ ethanol than in $100 \% \mathrm{v} / \mathrm{v}$ PG. These terpenes in $50 \% \mathrm{v} / \mathrm{v}$ ethanol were predicted to provide the required therapeutic plasma concentration and daily-permeated amounts of the drug. Limonene oxide showed higher enhancement in both solvents, which was attributed to its less bulky structure. The terpenes in both solvents did not increase the partition of HP. Instrumental studies showed that these terpenes in $50 \% \mathrm{v} / \mathrm{v}$ ethanol extracted the SC lipids, disrupted the bilayer packing and partially fluidised the lipids. Limonene oxide in $100 \% \mathrm{v} / \mathrm{v}$ PG possibly disrupted the lipid bilayer, whilst leaving the overall bilayer structure intact and pinene oxide in the same vehicle fluidised the lipids within the ordered environment. This study showed that the mode of interactions of terpenes with $\mathrm{SC}$ were different in two solvent systems.
\end{abstract}

Key words haloperidol; terpene; solvent; permeation; enhancement mechanism

Terpenes are constituents of essential oils obtained from various parts of plants and are widely used in perfumes, flavorings and in topical formulations. ${ }^{1,2}$ ) Terpenes are less toxic compounds with low irritancy and designated as generally recognized as safe (GRAS) by FDA and were reported to enhance the percutaneous absorption of both hydrophilic and lipophilic drugs. ${ }^{1,2)}$ They belong to various chemical classes like hydrocarbons, alcohols, oxides and ketones. The oxide terpenes were reported to increase the permeation of various drugs including 5-fluorouracil, ${ }^{2)}$ caffeine, ${ }^{1)}$ diclofenac sodium $^{3)}$ and tamoxifen. ${ }^{4)}$ Ethanol and propylene glycol (PG), widely used solvents in pharmaceutical formulations, are common vehicles for terpenes in transdermal studies. $\left.{ }^{5}\right)$ These solvents were reported to enhance permeation of many drugs and to have synergy with some terpenes in permeation enhancement. ${ }^{6-8)}$ The low systemic toxicity and local tolerability profiles for both solvents are well established. ${ }^{5}$

The stratum corneum (SC), the uppermost layer of the skin, is primarily responsible for the resistance to drug permeation. Terpenes can increase the permeation by one or more of the following mechanisms: interacting with the SC lipids and/or keratin, and increasing the solubility of the drug into SC lipids. ${ }^{2)}$ However, the interaction of terpenes with SC from various solvents may not be similar due to differences in physico-chemical properties of these solvents and their interactions with SC. These interactions can be determined by instrumental methods, such as, Fourier transform infrared spectroscopy (FT-IR) and differential scanning calorimetry (DSC). The FT-IR provides information about the molecular and conformational changes in SC lipids and proteins, whereas DSC provides information about their thermotropic behaviour. ${ }^{9)}$ Therefore both methods provide independent and complementary data about the interaction of terpenes with SC in the presence of different solvents. The partitioning of a drug from terpenes in $50 \% \mathrm{v} / \mathrm{v}$ ethanol or $100 \% \mathrm{v} / \mathrm{v}$
PG to SC can be determined by using drug-SC binding studies.

Haloperidol (HP), an antipsychotic drug, is a lipophilic drug and has low molecular weight (375.9). It is given in a low daily dose $(3-10 \mathrm{mg})$ in maintenance therapy to prevent the relapse of the psychosis. The suitability of HP for the development of transdermal formulation was discussed elsewhere. ${ }^{10,11)}$ In this work, effects of 5\% w/v (+) limonene oxide and $5 \% \mathrm{w} / \mathrm{v} \alpha$-pinene oxide in $50 \% \mathrm{v} / \mathrm{v}$ ethanol or in $100 \% \mathrm{v} / \mathrm{v} \mathrm{PG}$ on the permeation and partition of HP through human skin and the mechanisms of interaction of terpenes in either solvents with SC, using FT-IR and DSC were studied. Since ethanol at greater than $50 \% \mathrm{v} / \mathrm{v}$ causes excessive dehydration of the skin and was also reported to have counterproductive effect on the permeation enhancement of some drugs, $50 \% \mathrm{v} / \mathrm{v}$ ethanol was therefore chosen as one of the solvents in this study. ${ }^{4,12}$ Pinene oxide at $5 \% \mathrm{w} / \mathrm{v}$ concentration is miscible with both $50 \% \mathrm{v} / \mathrm{v}$ ethanol and $100 \mathrm{v} / \mathrm{v}$ PG; whereas limonene oxide at $5 \% \mathrm{w} / \mathrm{v}$ concentration is miscible with $100 \% \mathrm{v} / \mathrm{v}$ PG, but can only be dispersed in $50 \% \mathrm{v} / \mathrm{v}$ ethanol.

\section{MATERIALS AND METHODS}

Materials Haloperidol, droperidol, DL-lactic acid, antibiotic antimycotic solution $(100 \times)$ and sodium di-hydrogen phosphate monohydrate were purchased from Sigma Chemical Company and (+) limonene oxide $(97 \%), \alpha$-pinene oxide (97\%) from Aldrich Chemical Company. All other chemical reagents were of at least reagent grade and all materials were used as supplied.

Analytical Method Drug concentrations were determined by reversed phase HPLC $\left(\mathrm{C}_{18}\right.$ column, Hewlett Packard Pte Ltd., Germany) at $254 \mathrm{~nm}$. The mobile phase consisted of $0.05 \mathrm{M}$ phosphate buffer $\mathrm{pH}$ adjusted to 3 and acetonitrile in the ratio of $50: 50$. Droperidol was used as an 


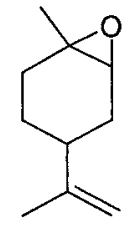

(+) Limonene oxide

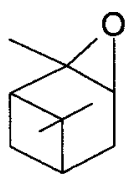

$\alpha$ - Pinene oxide

Fig. 1. Chemical Structures of Terpene Enhancers

internal standard. The flow rate was $1.3 \mathrm{ml} / \mathrm{min}$ and injection volume was $100 \mu$ l. The retention times of the internal standard and drug were approximately 4 and $6.5 \mathrm{~min}$, respectively. The mean peak area ratios of the drug and the internal standard in $0.03 \%(\mathrm{v} / \mathrm{v})$ lactic acid were linearly related to the drug concentrations for the samples containing $1 \mu \mathrm{g} / \mathrm{ml}$ to $7 \mu \mathrm{g} / \mathrm{ml}(r=0.9999)$. The intraday and interday coefficient of variations for all concentrations varied from $2.45 \%$ to $9.81 \%$

Solubility Studies Excess of HP was added to $50 \% \mathrm{v} / \mathrm{v}$ ethanol or $100 \% \mathrm{v} / \mathrm{v}$ PG containing antibacterial antimycotic solution (1 in 100 dilution) with or without enhancers and stirred for $24 \mathrm{~h}$ at $32 \pm 1{ }^{\circ} \mathrm{C}$ over an immersible magnetic stirring bed kept in a water bath. These samples were filtered through $0.45 \mu \mathrm{m}$ teflon filter units using a gas-tight syringe (Hamilton Pte Ltd., Switzerland). Saturated drug concentrations were determined by HPLC in triplicate after appropriate dilution with $0.03 \%$ lactic acid solution. Dilution with lactic acid solution phased out the terpenes but upon vortexing, the terpenes dispersed uniformly throughout the sample, thereby facilitating further dilution to the concentration of the drug within the range of the calibration curve. The final samples used for analysis were clear solutions. Saturated drug solutions were used for the permeation studies.

Preparation of Human Epidermis Malay and Chinese female skins were obtained from plastic surgery performed at the Singapore General Hospital, Singapore. Because human skin is in short supply, skins of both races were used assuming that the permeation and enhancement mechanism would be similar. Malay skin was used for permeation, SC binding and FT-IR studies and Chinese skin was used for DSC studies. Epidermal membranes were prepared by heat separation technique. ${ }^{13)}$ Whole skin was immersed in water at $60^{\circ} \mathrm{C}$ for $2 \mathrm{~min}$, followed by careful removal of the epidermis. Samples were stored at $-80{ }^{\circ} \mathrm{C}$ until used. Prior to permeation experiments, membranes with SC side up were floated over $0.9 \%$ $(w / v)$ sodium chloride solution containing antibacterial antimycotic solution ( 1 in 100 dilution) at $21 \pm 1^{\circ} \mathrm{C}$ for $3 \mathrm{~d}$.

Preparation of Stratum Corneum The human epidermal membranes with $\mathrm{SC}$ side up were incubated in petridishes over filter papers imbibed with $0.1 \%(\mathrm{w} / \mathrm{v})$ trypsin in $0.5 \%(\mathrm{w} / \mathrm{v})$ sodium bicarbonate solution at $37 \pm 1{ }^{\circ} \mathrm{C}$ for $3 \mathrm{~h} .{ }^{13)}$ The SC was removed, thoroughly washed and dried in a vacuum dessicator. After $24 \mathrm{~h}, \mathrm{SC}$ was dipped in acetone solution for $20 \mathrm{~s}$ to remove sebaceous lipids and dried again.

Permeation Studies Amber glass Franz-type diffusion cells were used for these permeation studies. The fully hydrated human epidermis was mounted between the donor and receptor compartments and excessive skin at the sides was trimmed off to minimize lateral diffusion. SC was arranged to face towards the donor compartment and the available skin area for permeation was approximately $1 \mathrm{~cm}^{2}$. Prior to mounting, high vacuum silicone grease was applied onto the donor and receptor compartments. Care was exercised to prevent the spread of the grease to the permeation area of the skin. One-ml of saturated drug solution in $50 \% \mathrm{v} / \mathrm{v}$ ethanol or $100 \% \mathrm{v} / \mathrm{v}$ PG with or without enhancers was added to the donor compartment. Saturated solutions were used for the diffusion experiments to ensure a maximal chemical potential of the drug. Since the solubility of HP in $0.03 \%$ lactic acid solution is approximately $1 \mathrm{mg} / \mathrm{ml},{ }^{10,11)} 0.03 \%$ lactic acid solution containing $1 \% \mathrm{v} / \mathrm{v}$ antibacterial antimycotic solution was placed in the receptor compartment to create a pseudo-sink condition. The $\mathrm{pH}$ of the receptor solution was approximately 3 but that did not affect the integrity of the epidermis as consistent flux values were obtained from all the permeation experiments of the current and the earlier experiments. ${ }^{10,11)}$ The receptor solution was thoroughly degassed to prevent the formation of bubbles beneath the membrane. An antibacterial and antimycotic solution was added to both donor and receptor solutions to maintain the integrity of the skin throughout the experiment and to minimize the microbial contamination in samples during the analysis. The donor compartment was covered with parafilm to minimize the evaporation of the solution. The sampling port was occluded with aluminum foil for the same purpose. The diffusion cells were placed over a heater/stirrer block (PermeGear, U.S.A.), which was covered to minimize the degradation of the drug from light and the content of the receiver compartment was stirred at $37 \pm 1^{\circ} \mathrm{C}$. Aliquots of $300 \mu \mathrm{l}$ were withdrawn periodically and replaced with the same volume of receptor fluid for $48 \mathrm{~h}$.

Stratum Corneum Binding Studies Binding of the drug to the pulverized SC from the control or terpene solutions was determined. ${ }^{14)}$ The SC was pulverized in a mortar with pestle and the particles that passed through 48-mesh but retained by 80 -mesh sieve were used $(180-300 \mu \mathrm{m})$. Approximately $1 \mathrm{mg}$ of SC powder was hydrated over saturated potassium sulphate solution for $3 \mathrm{~d}$. One $\mathrm{ml}$ of sub saturated drug solution in $50 \% \mathrm{v} / \mathrm{v}$ ethanol or $100 \% \mathrm{v} / \mathrm{v}$ PG with or without enhancers was added to SC powder and with frequent vortexing, the system was allowed to equilibrate at $21 \pm 1^{\circ} \mathrm{C}$ for $2 \mathrm{~d}$, same duration as that of the permeation studies. The supernatant solution, which was obtained at the end of $2 \mathrm{~d}$ by centrifugation, was analyzed for the drug content. The amount of the drug bound to SC was calculated by subtracting the amount of the drug present in the supernatant from the initial drug concentration.

Fourier Transform Infrared Spectroscopy (FT-IR) SC was cut into small circular discs with an approximate diameter of $1.5 \mathrm{~cm}$ and floated over $0.9 \%(\mathrm{w} / \mathrm{v})$ sodium chloride solution containing an antibacterial and antimycotic solution for $3 \mathrm{~d}$. Then these discs were thoroughly blotted over filter paper and the FT-IR (JASCO, FT/IR-430) spectra were recorded in the frequency range 400 to $4000 \mathrm{~cm}^{-1}$, with $2 \mathrm{~cm}^{-1}$ resolution. Each spectrum was an average of 60 scans. The SC discs were kept in $1.7 \mathrm{ml}$ of $50 \% \mathrm{v} / \mathrm{v}$ ethanol or $100 \% \mathrm{v} / \mathrm{v}$ PG with or without $5 \% \mathrm{w} / \mathrm{v}$ terpenes $\left(1 \mathrm{~cm}^{2}\right.$ of the SC treated with $1 \mathrm{ml}$ of enhancer solution) at $21 \pm 1^{\circ} \mathrm{C}$ for $2 \mathrm{~d}$, same as the duration of permeation studies. After $2 \mathrm{~d}$, the SC discs were thoroughly washed, blotted dry and the FT- 
IR spectra were taken. Each sample served as its own control.

Differential Scanning Calorimetry Approximately $20 \pm 0.5 \mathrm{mg}$ of SC was taken and hydrated over saturated potassium sulphate solution for 3 to $4 \mathrm{~d}$. Then the SC was blotted to obtain $20-25 \%$ hydration and kept in $12 \mathrm{ml}$ of $50 \% \mathrm{v} / \mathrm{v}$ ethanol or $100 \% \mathrm{v} / \mathrm{v}$ PG with or without $5 \% \mathrm{w} / \mathrm{v}$ enhancer for $48 \mathrm{~h}$ or $7 \mathrm{ml}$ of $50 \% \mathrm{v} / \mathrm{v}$ ethanol with or without $5 \% \mathrm{w} / \mathrm{v}$ enhancer for $12 \mathrm{~h}$ at $21 \pm 1{ }^{\circ} \mathrm{C}$. After the enhancer treatment, the SC was removed and blotted to obtain hydration of $20-25 \%$, sealed in aluminium hermetic pans and equilibrated for $1 \mathrm{~h}$ prior to the DSC measurement (TA instruments, U.S.A.). The scanning rate was at $2{ }^{\circ} \mathrm{C} / \mathrm{min}$ over the temperature range $10^{\circ} \mathrm{C}$ to $140^{\circ} \mathrm{C}$.

percentage of hydration $=\{($ weight of the hydrated $\mathrm{SC}-$ weight of the dry $\mathrm{SC})$ /weight of the dry SC $\} \times 100$

Permeation Parameters The cumulative amount of drug ' $Q$ ' permeated through the skin with area ' $A$ ' in time ' $t$ ' from the donor solution at constant concentration ' $C o$ ' to the receptor phase at the sink condition was described by Okamato and co-workers ${ }^{15}$ according to the following equation:

$$
Q=A K^{\prime} C o\left[D^{\prime} t-\frac{1}{6}-\frac{1}{\pi^{2}} \sum_{n=1}^{\infty} \frac{(-1)^{n}}{n^{2}} e^{\left(-D^{\prime} n^{2} \pi^{2} t\right)}\right]
$$

Where $K^{\prime}$ is the activity parameter and $D^{\prime}$ is the diffusion parameter. A non-linear regression program (Graph Pad Prism $^{\mathrm{TM}}$, San Diego, CA, U.S.A.) with $n=5$ was used to fit the equation to the experimental data and $K^{\prime}$ and $D^{\prime}$ values were calculated. The following equations were used to calculate the permeability coefficient $(P)$, lag time $(L t)$ and flux $(J)$ from $K^{\prime}$ and $D^{\prime}$ values.

$$
\begin{aligned}
& P=K^{\prime} \cdot D^{\prime} \\
& L t=1 / 6 D^{\prime} \\
& J=P \cdot C o
\end{aligned}
$$

Where $C o$ is the saturated solubility of the drug. Following equations were used to evaluate the effect of the enhancers on permeability coefficient, lag time and flux.

$$
\begin{aligned}
& E I=\frac{[P] \text { with enhancer }}{[P] \text { without enhancer }} \\
& K r=\frac{\left[K^{\prime}\right] \text { with enhancer }}{\left[K^{\prime}\right] \text { without enhancer }}
\end{aligned}
$$

$$
D r=\frac{[L t] \text { with enhancer }}{[L t] \text { without enhancer }}
$$

Where $E I$ is the enhancer index, $K r$ is the coefficient of relative activity, $\mathrm{Dr}$ is the coefficient of relative diffusion.

It is possible to predict the steady state plasma concentrations (Pss) through the human skin in vivo using the following equation, if the drug were in a transdermal patch with an area $(T a)$ of $16 \mathrm{~cm}^{2}$.

$$
P s s=J \cdot T a / C l p
$$

Clp is plasma clearance of HP, which is $36.51 / h^{16)}$

Therapeutic transdermal daily dose $(T d)$ was calculated from the equation 9 where $F$ is the bioavailabilty in percentage after oral administration and $D o$ is the oral daily dose

$$
T d=D o \cdot F / 100
$$

The bioavailability of HP is $60 \%$ on average $\mathrm{e}^{17)}$ and its daily maintenance oral dose is $3-10 \mathrm{mg} .{ }^{18)}$

Permeated daily doses (Dss) from $16 \mathrm{~cm}^{2}$ transdermal patch was calculated from equation 10, where $t$ is $24 \mathrm{~h}$

$$
D s s=J \cdot T a \cdot t
$$

\section{RESULTS}

Permeation Both limonene oxide and pinene oxide in $50 \% \mathrm{v} / \mathrm{v}$ ethanol and $100 \% \mathrm{v} / \mathrm{v}$ PG increased the solubility, flux and permeability coefficient of HP significantly from that of the controls (Table 1) (One-way ANOVA with Tukey posthoc test) (Fig. 2). The enhancer index values indicate that limonene oxide enhanced permeation more than pinene oxide in both $50 \% \mathrm{v} / \mathrm{v}$ ethanol and $100 \% \mathrm{v} / \mathrm{v}$ PG and these enhancers showed greater enhancement effects in $50 \% \mathrm{v} / \mathrm{v}$ ethanol than in $100 \% \mathrm{v} / \mathrm{v}$ PG. Both enhancers in $50 \% \mathrm{v} / \mathrm{v}$ ethanol or $100 \% \mathrm{v} / \mathrm{v}$ PG increased solubility of HP to a similar extent. The terpenes in $50 \% \mathrm{v} / \mathrm{v}$ ethanol did not significantly increase the lag time from that of the control whereas terpenes in $100 \% \mathrm{v} / \mathrm{v}$ PG significantly increased lag time from that of the control. The predicted steady state plasma

\begin{tabular}{|c|c|c|c|c|c|c|c|}
\hline Enhancer & $K^{\prime} \cdot 10$ & $D^{\prime} \cdot 10^{2}$ & Co $(\mathrm{mg} / \mathrm{ml})$ & $L t(\mathrm{~h})$ & $J \cdot 10^{3}\left(\mathrm{mg} / \mathrm{cm}^{2} / \mathrm{h}\right)$ & $P \cdot 10^{3}(\mathrm{~cm} / \mathrm{h})$ & EI \\
\hline $50 \% \mathrm{v} / \mathrm{v}$ ethanol & $0.50 \pm 0.16$ & $1.80 \pm 0.46$ & $0.65 \pm 0.02$ & $9.72 \pm 2.72$ & $0.56 \pm 0.05$ & $0.85 \pm 0.09$ & - \\
\hline Limonene oxide $/ 50 \% \mathrm{v} / \mathrm{v}$ ethanol & $9.54 \pm 0.27$ & $1.28 \pm 0.05$ & $1.85 \pm 0.07 *$ & $13.05 \pm 0.55$ & $22.54 \pm 1.04 *$ & $12.18 \pm 0.17 *$ & 14.33 \\
\hline Pinene oxide $/ 50 \% \mathrm{v} / \mathrm{v}$ ethanol & $4.69 \pm 0.99$ & $1.69 \pm 0.16$ & $1.74 \pm 0.09 *$ & $9.95 \pm 0.92$ & $13.57 \pm 1.53^{*}$ & $7.80 \pm 0.94 *$ & 9.18 \\
\hline Enhancer & $K^{\prime} \cdot 10^{2}$ & $D^{\prime} \cdot 10^{2}$ & Co $(\mathrm{mg} / \mathrm{ml})$ & $L t(\mathrm{~h})$ & $J \cdot 10^{3}\left(\mathrm{mg} / \mathrm{cm}^{2} / \mathrm{h}\right)$ & $P \cdot 10^{4}(\mathrm{~cm} / \mathrm{h})$ & $E I$ \\
\hline $100 \% \mathrm{v} / \mathrm{v}$ PG & $0.29 \pm 0.02$ & $1.88 \pm 0.14$ & $2.74 \pm 0.01$ & $8.88 \pm 0.69$ & $0.15 \pm 0.02$ & $0.55 \pm 0.05$ & - \\
\hline Limonene oxide/ $100 \%$ v/v PG & $3.24 \pm 0.42$ & $1.20 \pm 0.21$ & $4.02 \pm 0.09^{*}$ & $14.11 \pm 2.26^{*}$ & $1.56 \pm 0.30 *$ & $3.90 \pm 0.82 *$ & 7.09 \\
\hline Pinene oxide $/ 100 \%$ v/v PG & $2.10 \pm 0.47$ & $1.08 \pm 0.03$ & $4.37 \pm 0.08^{*}$ & $15.43 \pm 0.41 *$ & $0.98 \pm 0.19^{*}$ & $2.27 \pm 0.47^{*}$ & 4.13 \\
\hline
\end{tabular}
concentration and daily-permeated amounts were significantly higher with both enhancers in $50 \% \mathrm{v} / \mathrm{v}$ ethanol and $100 \% \mathrm{v} / \mathrm{v}$ PG from control values (Table 3 ).

SC Binding Studies The enhancers in both $50 \% \mathrm{v} / \mathrm{v}$ ethanol and $100 \% \mathrm{v} / \mathrm{v}$ PG did not significantly increase the partition coefficient of HP from that of the control values (Table 4). In fact, both terpenes in $100 \% \mathrm{v} / \mathrm{v} P G$ and

Table 1. Activity Parameter $\left(K^{\prime}\right)$, Diffusion Parameter $\left(D^{\prime}\right)$, Solubility $(C o)$, Lag Time $(L t)$, Flux $(J)$, and Permeability Coefficient $(P)$ of Haloperidol and Enhancer Index $(E I)$ in the Absence and Presence of the Terpenes in $50 \% \mathrm{v} / \mathrm{v}$ Ethanol and $100 \% \mathrm{v} / \mathrm{v} \mathrm{PG}^{a}$

a) Mean \pm S.D. $(n=3)$. * One-way ANOVA Tukey posthoc test $(p<0.05)$. 


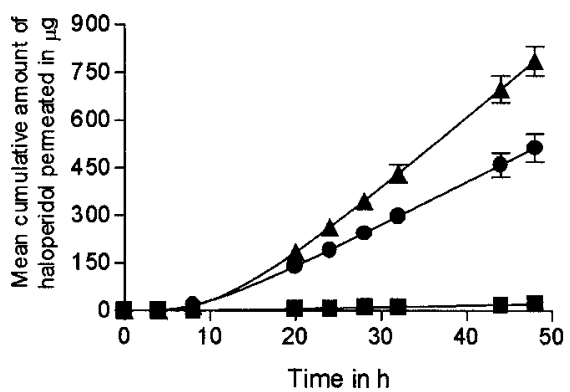

I

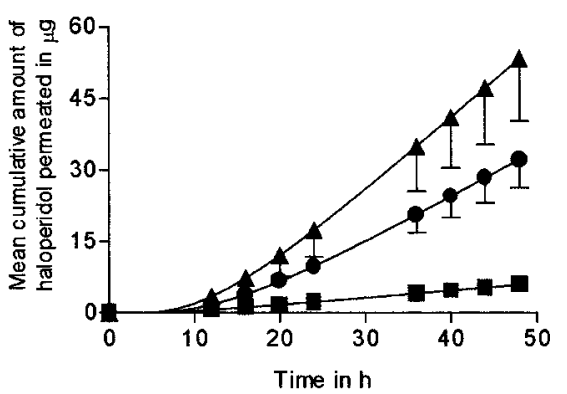

II

Fig. 2. Time Course of Mean Cumulative Amounts of Haloperidol Permeated through $1 \mathrm{~cm}^{2}$ of Human Epidermal Membrane in the Absence and Presence of $5 \% \mathrm{w} / \mathrm{v}$ Terpenes in [I] $50 \% \mathrm{v} / \mathrm{v}$ Ethanol and [II] $100 \% \mathrm{v} / \mathrm{v}$ PG and Their Corresponding Theoretical Fitting Curves

Key (ם) control, ( $)$ pinene oxide, $(\boldsymbol{\Delta})$ limonene oxide. Each point represents mean \pm S.D. $(n=3)$.

Table 2. Effect of Terpenes in $50 \% \mathrm{v} / \mathrm{v}$ Ethanol and $100 \% \mathrm{v} / \mathrm{v}$ PG on the Permeation Profile of Haloperidol Expressed in Relation to the Relative Activity Parameter $(\mathrm{Kr})$, Relative Diffusion Parameter $(\mathrm{Dr})$ and Relative Solubility $(\mathrm{Cr})$

\begin{tabular}{|c|c|c|c|c|c|c|}
\hline \multirow{2}{*}{ Enhancer } & \multicolumn{3}{|c|}{$50 \% \mathrm{v} / \mathrm{v}$ ethanol } & \multicolumn{3}{|c|}{$100 \% \mathrm{v} / \mathrm{v} \mathrm{PG}$} \\
\hline & $K r$ & $D r$ & $\mathrm{Cr}$ & $K r$ & $D r$ & $\mathrm{Cr}$ \\
\hline Limonene oxide & 19.08 & 0.74 & 2.85 & 11.17 & 0.63 & 1.47 \\
\hline Pinene oxide & 9.38 & 0.98 & 2.68 & 7.24 & 0.58 & 1.59 \\
\hline
\end{tabular}

Table 3. Predictive Permeated Daily Amounts (Dss) and Predictive Plasma Levels (Pss) at Steady State Conditions for Haloperidol in Absence and Presence of Terpenes in 50\% v/v Ethanol and $100 \% \mathrm{v} / \mathrm{v} \mathrm{PG}^{a)}$

\begin{tabular}{|c|c|c|c|c|}
\hline \multirow{2}{*}{ Enhancer } & \multicolumn{2}{|c|}{$50 \% \mathrm{v} / \mathrm{v}$ ethanol } & \multicolumn{2}{|c|}{$100 \% \mathrm{v} / \mathrm{v} \mathrm{PG}$} \\
\hline & $D s s(\mathrm{mg} / \mathrm{d})$ & Pss (ng/ml) & Dss (mg/d) & Pss $(\mathrm{ng} / \mathrm{ml})$ \\
\hline Control & $0.21 \pm 0.02$ & $0.24 \pm 0.03$ & $0.06 \pm 0.01$ & $0.07 \pm 0.01$ \\
\hline Limonene oxide & $8.66 \pm 0.40^{*}$ & $9.88 \pm 0.46^{*}$ & $0.60 \pm 0.11 *$ & $0.68 \pm 0.13 *$ \\
\hline Pinene oxide & $5.21 \pm 0.59^{*}$ & $5.95 \pm 0.67 *$ & $0.38 \pm 0.07 *$ & $0.43 \pm 0.08^{*}$ \\
\hline
\end{tabular}

a) Mean \pm S.D. $(n=3)$. Transdermal daily dose $1.8-6 \mathrm{mg} / \mathrm{d}$. Therapeutic plasma concentration $0.8-5.15 \mathrm{ng} / \mathrm{ml}$. * One-way Anova Tukey posthoc test $(p<0.05)$.

Table 4. Partition Coefficients of Haloperidol in Powdered Human Stratum Corneum/Control or Terpene Solution ${ }^{a)}$

\begin{tabular}{lcc}
\hline \hline \multirow{2}{*}{ Enhancer } & \multicolumn{2}{c}{ Partition coefficient } \\
\cline { 2 - 3 } & $50 \% \mathrm{v} / \mathrm{v}$ ethanol & $100 \% \mathrm{v} / \mathrm{v} \mathrm{PG}$ \\
\hline Control & $88.61 \pm 17.16$ & $72.52 \pm 17.16$ \\
Limonene oxide & $53.16 \pm 7.52$ & $22.14 \pm 4.43$ \\
Pinene oxide & $102.35 \pm 16.05$ & $38.40 \pm 11.82$ \\
\hline
\end{tabular}

a) Mean \pm S.D. $(n=3)$. Partition coefficient $=$ concentration of haloperidol in $1000 \mathrm{mg}$ of powdered human stratum corneum/concentration of haloperidol in $1000 \mathrm{mg}$ of control or enhancer solution.

limonene oxide in $50 \% \mathrm{v} / \mathrm{v}$ ethanol decreased the partition coefficient compared to that of the control.

Fourier Transform Infrared Spectroscopy Many of the IR spectra bands of SC can be attributed to lipid or protein molecular vibrations. The keratin backbone was reported to give amide A, amide I and amide II peaks at $c a .3300$ $\mathrm{cm}^{-1}, c a .1650 \mathrm{~cm}^{-1}$ and $c a .1550 \mathrm{~cm}^{-1}$, respectively. The hydrocarbon chains of lipids cause asymmetric and symmetric $\mathrm{CH}_{2}$ vibrations at 2920 and $2850 \mathrm{~cm}^{-1}$, respectively. ${ }^{19}$ ) The heights and areas of these two $\mathrm{CH}_{2}$ peaks are proportional to the amount of the lipids present in SC. So any extraction of the lipids by the enhancer results in decreased peak heights and smaller peak areas. ${ }^{5)}$ Some enhancers may fluidise the SC lipids, which can be noted from an increase in bandwidths at half height of $\mathrm{CH}_{2}$ stretching peaks alone or a shift of these peaks to a higher wave number associated with an increase in bandwidths at half height. ${ }^{20)}$ An increase in bandwidth alone indicates increase in rates and amplitudes of the translational and rotational motions of individual $\mathrm{CH}_{2}$ groups and acyl chains within the ordered environment. This conclusion can be drawn when the frequency of lipid peaks does not change after enhancer treatment and slight increases occur only in the bandwidths. The shift of the peak to a higher wavenumber associated with an increase in bandwidth is due to the conversion of trans conformers to gauche conformers along the acyl chains, which indicates the decrease in the degree of organisation of the lipid acyl chains. The higher the gauche conformers along the acyl chain the higher the fluidity of the lipids. The peak heights, areas and peak widths at half height were measured after making base line correction. The IR spectra of SC treated with $50 \% \mathrm{v} / \mathrm{v}$ ethanol, $100 \% \mathrm{v} / \mathrm{v} \mathrm{PG}$, terpenes in $50 \% \mathrm{v} / \mathrm{v}$ ethanol and $100 \% \mathrm{v} / \mathrm{v}$ PG showed significant decreases in heights and areas of lipid peaks compared to the IR spectra of SC prior to the treatments (Paired ' $t$ ' test $p<0.05$ ) (Tables 5, 6). The percentage decreases in peak heights and areas were significantly higher with the terpenes in $50 \% \mathrm{v} / \mathrm{v}$ ethanol compared to $50 \% \mathrm{v} / \mathrm{v}$ ethanol alone (Table 5) (One-way ANOVA with Tukey posthoc test) (Fig. 3). The greatest decreases in peak height and area were observed with limonene oxide. The percentage decreases in peak heights and areas with terpenes in $100 \% \mathrm{v} / \mathrm{v}$ PG were not significantly different from that of the pure $\mathrm{PG}$ with the exception of the peak area of asymmetric $\mathrm{CH}_{2}$ stretching of SC treated with pinene oxide (Table 6, Fig. 3). Ethanol $(50 \% \mathrm{v} / \mathrm{v}), 100 \% \mathrm{v} / \mathrm{v} \mathrm{PG}$, terpenes in $50 \% \mathrm{v} / \mathrm{v}$ ethanol and limonene oxide in $100 \% \mathrm{v} / \mathrm{v}$ PG did not increase the peak widths at half height where as pinene oxide in $100 \%$ v/v PG increased peak widths (Tables 5, 6). The terpenes and controls did not shift the frequency of lipid peaks.

Differential Scanning Calorimetry The thermogram of hydrated SC showed three endotherms at $62^{\circ} \mathrm{C}, 79^{\circ} \mathrm{C}$ and 
Table 5. Peak Height, Area and Width of Asymmetric and Symmetric $\mathrm{CH}_{2}$ Stretchings before and after Treatment of Stratum Corneum with 50\% v/v Ethanol or Terpenes in $50 \% \mathrm{v} / \mathrm{v}$ Ethanol Solutions for $48 \mathrm{~h}$ and Their Percentage Decrease ${ }^{a}$

\begin{tabular}{|c|c|c|c|c|c|c|c|c|c|}
\hline \multirow{2}{*}{ Enhancer } & \multicolumn{3}{|c|}{ Peak height } & \multicolumn{3}{|c|}{ Peak area } & \multicolumn{3}{|c|}{ Peak width } \\
\hline & $\begin{array}{c}\text { Before } \\
\text { treatment }\end{array}$ & $\begin{array}{c}\text { After } \\
\text { treatment }\end{array}$ & $\%$ Decrease & $\begin{array}{c}\text { Before } \\
\text { treatment }\end{array}$ & $\begin{array}{c}\text { After } \\
\text { treatment }\end{array}$ & $\%$ Decrease & $\begin{array}{c}\text { Before } \\
\text { treatment }\end{array}$ & $\begin{array}{c}\text { After } \\
\text { treatment }\end{array}$ & $\%$ Decrease \\
\hline & & & & Asymmetric & $\mathrm{CH}_{2}$ & Stretching & & & \\
\hline Control & $0.48 \pm 0.00$ & $0.44 \pm 0.00$ & $9.55 \pm 0.55$ & $15.53 \pm 1.06$ & $14.02 \pm 1.10$ & $9.75 \pm 1.44$ & $20.59 \pm 0.53$ & $19.61 \pm 0.41$ & $4.53 \pm 0.57$ \\
\hline Limonene oxide & $0.39 \pm 0.01$ & $0.31 \pm 0.01$ & $21.04 \pm 1.19 *$ & $12.20 \pm 0.19$ & $9.65 \pm 0.20$ & $20.89 \pm 0.97 *$ & $19.34 \pm 0.58$ & $18.17 \pm 0.56$ & $6.05 \pm 0.57 *$ \\
\hline \multirow[t]{2}{*}{ Pinene oxide } & $0.39 \pm 0.02$ & $0.34 \pm 0.01$ & $13.08 \pm 1.02 *$ & $12.11 \pm 0.52$ & $10.25 \pm 0.40$ & $15.38 \pm 0.36^{*}$ & $18.79 \pm 1.18$ & $17.73 \pm 1.12$ & $5.62 \pm 0.1$ \\
\hline & & & & Symmetric & $\mathrm{CH}_{2}$ & Stretching & & & \\
\hline Control & $0.27 \pm 0.01$ & $0.25 \pm 0.01$ & $6.35 \pm 0.94$ & $2.63 \pm 0.19$ & $2.49 \pm 0.16$ & $5.45 \pm 0.68$ & $8.44 \pm 0.49$ & $8.13 \pm 0.43$ & $3.67 \pm 0.67$ \\
\hline Limonene oxide & $0.23 \pm 0.01$ & $0.18 \pm 0.01$ & $20.99 \pm 1.46^{*}$ & $2.23 \pm 0.19$ & $1.71 \pm 0.17$ & $23.39 \pm 2.39^{*}$ & $8.24 \pm 0.42$ & $7.80 \pm 0.39$ & $5.32 \pm 0.57 *$ \\
\hline Pinene oxide & $0.23 \pm 0.01$ & $0.20 \pm 0.01$ & $11.94 \pm 0.15^{*}$ & $2.09 \pm 0.09$ & $1.78 \pm 0.06$ & $14.84 \pm 0.51 *$ & $8.32 \pm 0.51$ & $7.93 \pm 0.51$ & $4.76 \pm 0.36$ \\
\hline
\end{tabular}

a) Mean \pm S.D. $(n=3)$. Percentage decrease in peak height or area $=\{($ peak height or area or width before treatment - peak height or area or width after treatment $) \times 100\} /$ peak height or area or width before treatment. * One-way Anova Tukey posthoc test $(p<0.05)$.

Table 6. Peak Height, Area and Width of Asymmetric and Symmetric $\mathrm{CH}_{2}$ Stretchings before and after Treatment of Stratum Corneum with $100 \%$ v/v PG or Terpenes in $100 \% \mathrm{v} / \mathrm{v}$ PG Solutions for $48 \mathrm{~h}$ and Their Percentage Decrease ${ }^{a)}$

\begin{tabular}{|c|c|c|c|c|c|c|c|c|c|}
\hline \multirow{2}{*}{ Enhancer } & \multicolumn{3}{|c|}{ Peak height } & \multicolumn{3}{|c|}{ Peak area } & \multicolumn{3}{|c|}{ Peak width } \\
\hline & $\begin{array}{c}\text { Before } \\
\text { treatment }\end{array}$ & $\begin{array}{c}\text { After } \\
\text { treatment }\end{array}$ & $\%$ Decrease & $\begin{array}{c}\text { Before } \\
\text { treatment }\end{array}$ & $\begin{array}{c}\text { After } \\
\text { treatment }\end{array}$ & $\%$ Decrease & $\begin{array}{c}\text { Before } \\
\text { treatment }\end{array}$ & $\begin{array}{c}\text { After } \\
\text { treatment }\end{array}$ & $\%$ Decrease \\
\hline & & & & Asymmetric & $\mathrm{CH}_{2}$ & Stretching & & & \\
\hline Control & $0.50 \pm 0.07$ & $0.43 \pm 0.05$ & $12.91 \pm 2.60$ & $16.27 \pm 1.86$ & $14.04 \pm 1.41$ & $13.59 \pm 2.08$ & $20.49 \pm 0.37$ & $19.23 \pm 0.52$ & $6.59 \pm 0.96$ \\
\hline Limonene oxide & $0.41 \pm 0.03$ & $0.36 \pm 0.02$ & $12.22 \pm 1.95$ & $13.22 \pm 0.83$ & $11.54 \pm 0.65$ & $12.68 \pm 1.18$ & $18.95 \pm 0.45$ & $17.85 \pm 0.32$ & $5.82 \pm 0.65$ \\
\hline \multirow[t]{2}{*}{ Pinene oxide } & $0.42 \pm 0.01$ & $0.38 \pm 0.01$ & $9.58 \pm 1.41$ & $13.31 \pm 0.62$ & $12.13 \pm 0.59$ & $8.88 \pm 0.89^{*}$ & $18.50 \pm 0.63$ & $19.27 \pm 0.59$ & $-4.14 \pm 0.37 *$ \\
\hline & & & & Symmetric & $\mathrm{CH}_{2}$ & Stretching & & & \\
\hline Control & $0.30 \pm 0.06$ & $0.27 \pm 0.06$ & $12.85 \pm 1.89$ & $3.11 \pm 0.70$ & $2.71 \pm 0.56$ & $11.68 \pm 2.59$ & $8.50 \pm 0.52$ & $8.11 \pm 0.46$ & $4.81 \pm 0.80$ \\
\hline Limonene oxide & $0.24 \pm 0.01$ & $0.21 \pm 0.01$ & $11.87 \pm 1.17$ & $2.33 \pm 0.15$ & $2.07 \pm 0.10$ & $11.07 \pm 1.21$ & $8.39 \pm 0.48$ & $7.98 \pm 0.49$ & $4.81 \pm 0.45$ \\
\hline Pinene oxide & $0.25 \pm 0.00$ & $0.23 \pm 0.01$ & $9.57 \pm 1.36$ & $2.40 \pm 0.06$ & $2.14 \pm 0.04$ & $10.81 \pm 1.96$ & $8.13 \pm 0.20$ & $8.32 \pm 0.22$ & $-2.32 \pm 0.22 *$ \\
\hline
\end{tabular}

a) Mean \pm S.D. $(n=3)$. Percentage decrease in peak height or area $=\{($ peak height or area or width before treatment - peak height or area or width after treatment $) \times 100\} /$ peak height or area or width before treatment. * One-way Anova Tukey posthoc test $(p<0.05)$.

$95^{\circ} \mathrm{C}$. The first two peaks $\mathrm{T} 1$ and $\mathrm{T} 2$ were due to the melting of the lipids and the third peak T3 was due to the denaturation of protein. ${ }^{21)}$ Many workers reported another lipid peak at $32^{\circ} \mathrm{C}$ but that was not observed in our experiments, which may be due to the low enthalpy $(\Delta H)$ of this peak and therefore may require a slow heating rate. ${ }^{9)}$ However, this peak is unlikely to have major importance for investigating the mechanism of action of permeation enhancers. ${ }^{22)}$ There are different explanations why lipids melt in two stages. Although there is a wider acceptance that $\mathrm{T} 1$ is due to the melting of the lipid bilayer, the appearance of $\mathrm{T} 2$ is less clearly understood. T2 might be due to the melting of the lipids associated with the keratin ${ }^{23}$ ) or due to the disruption of polar head groups of lipids. ${ }^{24)}$ It was recently suggested that the non-random distribution of lipids in the intercellular bilayers, led to the melting of SC lipids in two stages; T1 and T2. ${ }^{25}$ ) Although lipids melt in two stages in the first heating run but in the second run of the same sample only one lipid peak was reported to appear and the enthalpy $(\Delta H)$ was approximately equivalent to the sum of the enthalpies of the two lipid peaks of the first run. ${ }^{26)}$ An endothermic peak is due to the transition of one phase to the other phase by heat absorption. Tm is the temperature at which these two phases of the transition are at equilibrium and it is represented by the temperature at the mid point of a peak. Cooperativity is related to the sharpness of a peak, which increases as the discretion of a compound corresponds to this phase transition in a sample increases. ${ }^{9)}$ Since the weight of the SC samples taken in all DSC experiments was $20 \pm 0.5 \mathrm{mg}$ for the comparison of thermograms, enthalpy values were equated with the peak areas regardless of the weight of the sample in the equation; $\Delta H=$ peak area/weight of the sample.

Treatment with $12 \mathrm{ml}$ of $50 \% \mathrm{v} / \mathrm{v}$ ethanol for $48 \mathrm{~h}$ reduced $\mathrm{T} 1$ and $\mathrm{T} 2$ peak areas, removed the protein peak and reduced $\mathrm{Tm} 1$ and $\mathrm{Tm} 2$ by approximately $7.0^{\circ} \mathrm{C}$ and $6.0^{\circ} \mathrm{C}$, respectively (Fig. 4). Lipid and protein endotherms were not observed upon treatment with terpenes in $50 \% \mathrm{v} / \mathrm{v}$ ethanol for $48 \mathrm{~h}$. The treatment of SC with $12 \mathrm{ml}$ of control or enhancer solution for $48 \mathrm{~h}$ was to mimic the conditions of the permeation experiment $\left(12 \mathrm{~cm}^{2}\right.$ of $\mathrm{SC}$ approximately weighed $20 \mathrm{mg}$ ). But a complete disappearance of peaks does not provide much information about the mechanism of action. So the treatment time of terpenes in $50 \% \mathrm{v} / \mathrm{v}$ ethanol was reduced to $12 \mathrm{~h}$ and the volume of enhancer solution used for 

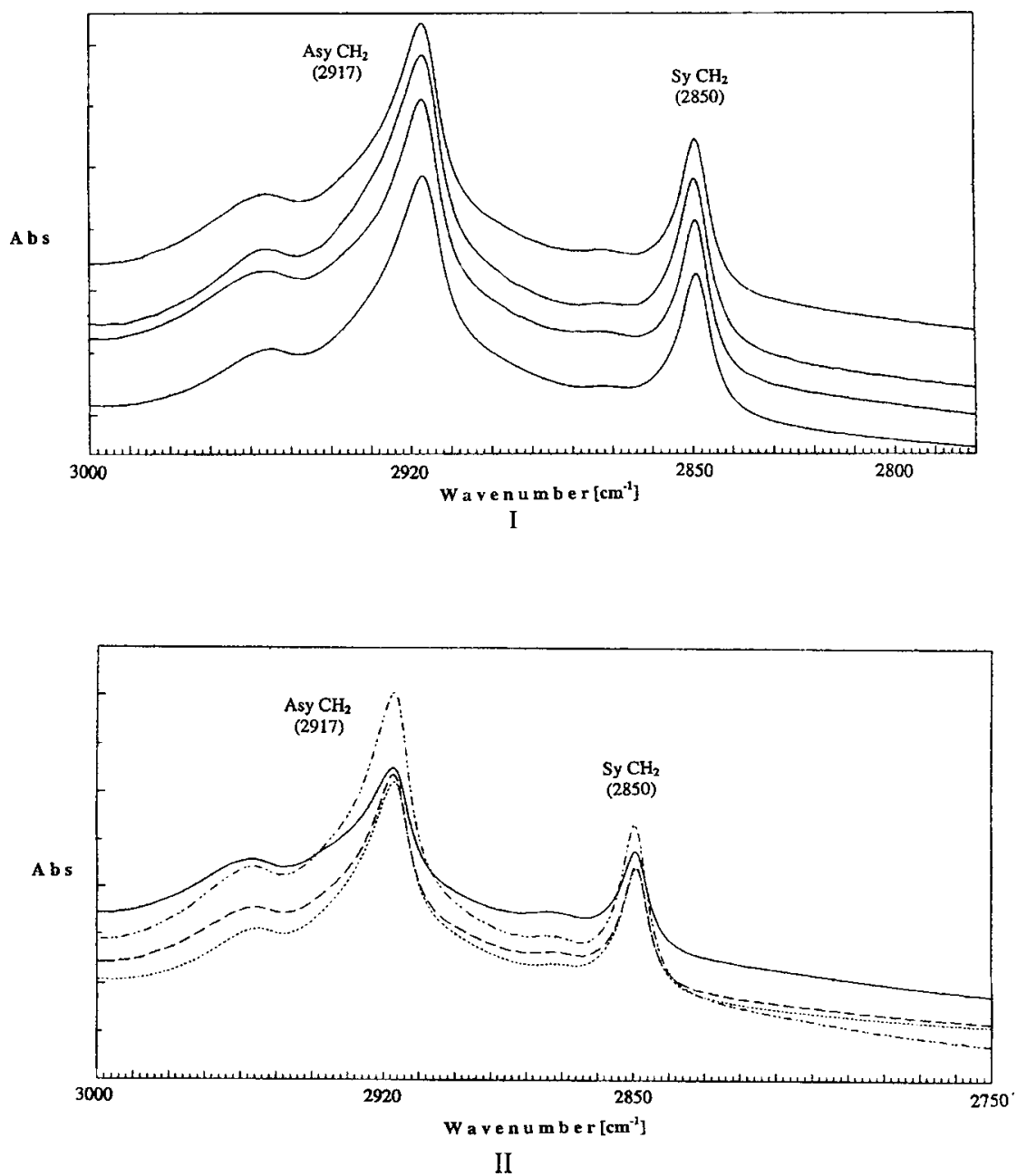

Fig. 3. Typical IR Spectra of SC Showing Reduction in $\mathrm{CH}_{2}$ Stretching Bands

[I] Untreated and treated with $50 \% \mathrm{v} / \mathrm{v}$ ethanol with or without $5 \% \mathrm{w} / \mathrm{v}$ terpenes for $48 \mathrm{~h}$. Top to bottom: SC untreated, SC treated with $50 \% \mathrm{v} / \mathrm{v}$ ethanol, pinene oxide $/ 50 \% \mathrm{v} / \mathrm{v}$ ethanol, limonene oxide $/ 50 \% \mathrm{v} / \mathrm{v}$ ethanol. [II] Untreated and treated with $100 \% \mathrm{v} / \mathrm{v}$ PG with or without $5 \% \mathrm{w} / \mathrm{v}$ terpenes for $48 \mathrm{~h}$. SC untreated $(-\cdots-), \mathrm{SC}$ treated with $100 \% \mathrm{v} / \mathrm{v}$ PG alone $(\cdots)$, limonene oxide $/ 100 \% \mathrm{v} / \mathrm{v}$ PG $(---)$, pinene oxide $/ 100 \% \mathrm{v} / \mathrm{v}$ PG $(-)$.

treating the $\mathrm{SC}$ was also decreased to $7 \mathrm{ml}$. Ethanol $(50 \%$ $\mathrm{v} / \mathrm{v}$ ) after a $12 \mathrm{~h}$ treatment reduced lipid peak areas, removed protein peak and decreased $\mathrm{Tm} 1$ and $\mathrm{Tm} 2$ by $5{ }^{\circ} \mathrm{C}$ and $3{ }^{\circ} \mathrm{C}$, respectively (Fig. 5). Limonene oxide in $50 \% \mathrm{v} / \mathrm{v}$ ethanol after a $12 \mathrm{~h}$ treatment produced a single large endotherm in the place of T1 and T2 peaks and the protein endotherm was absent. Pinene oxide after a $12 \mathrm{~h}$ treatment decreased cooperativity and peak area of $\mathrm{T} 1$ and removed $\mathrm{T} 3$ but did not appear to have much effect on T2. Pinene oxide also decreased Tm 1 and $\mathrm{Tm} 2$ by $26^{\circ} \mathrm{C}$ and $24^{\circ} \mathrm{C}$, respectively. Treatment with $12 \mathrm{ml}$ of $100 \% \mathrm{v} / \mathrm{v}$ PG alone for $48 \mathrm{~h}$ did not show significant effect on the peak areas and cooperativities of $\mathrm{T} 1$ and $\mathrm{T} 2$ from that of the untreated $\mathrm{SC}$ but reduced $\mathrm{Tm} 1$ and $\mathrm{Tm} 2$ by approximately $4.0^{\circ} \mathrm{C}$ and $3.0^{\circ} \mathrm{C}$, respectively (Fig. 6). Limonene oxide in $100 \% \mathrm{v} / \mathrm{v}$ PG did not appear to have much effect on the peak areas of T1 and T2 but appear to increase their cooperativities after a $48 \mathrm{~h}$ treatment. Pinene oxide in $100 \% \mathrm{v} / \mathrm{v}$ PG reduced $\mathrm{T} 1$ and $\mathrm{T} 2$ peak areas. Limonene oxide decreased $\mathrm{Tm} 1$ and $\operatorname{Tm} 2$ by $2{ }^{\circ} \mathrm{C}$ and $3{ }^{\circ} \mathrm{C}$, respectively, whereas pinene oxide decreased the same transition temperatures by $5.5^{\circ} \mathrm{C}$ and $6^{\circ} \mathrm{C}$, respectively from the control values. PG $(100 \% \mathrm{v} / \mathrm{v})$ and both terpenes in $100 \%$ $\mathrm{v} / \mathrm{v}$ PG removed the protein endotherm after a $48 \mathrm{~h}$ treatment.

\section{DISCUSSION}

An enhancer increases the permeation of the drug through the epidermis either by increasing the activity parameter of the drug in SC, or by decreasing the tortuous intercellular pathway in SC, or by both. ${ }^{16)}$ The relative activity parameter $(\mathrm{Kr})$ indicates the effect of enhancer on the activity parameter of the drug in $\mathrm{SC}$ whereas the relative diffusion parameter ( $D r$ ) relates to the lag time. The higher the $K r$ and $D r$ values, the higher the activity parameters and the lower the lag time values, respectively. An increase in activity parameter and/or a decrease in diffusion path length can be due to either one or more of the following mechanisms: fluidisation of SC lipids, extraction of lipids, increasing the solubility of the drug in $\mathrm{SC}$, enhancer interaction with the keratin. Since both terpenes in $50 \%$ v/v ethanol or $100 \%$ v/v PG increased $K r$ but decreased $\mathrm{Dr}$ below unity, the permeation enhancements were mainly due to an increase in the activity parameter of the drug in SC (Table 2). Since, limonene oxide in both solvents provided higher $K r$ values than pinene oxide in the same solvents, limonene oxide is an effective enhancer for HP permeation. Both these terpenes provided higher $\mathrm{Kr}$ values in $50 \% \mathrm{v} / \mathrm{v}$ ethanol than in $100 \% \mathrm{v} / \mathrm{v} \mathrm{PG}, 50 \% \mathrm{v} / \mathrm{v}$ 


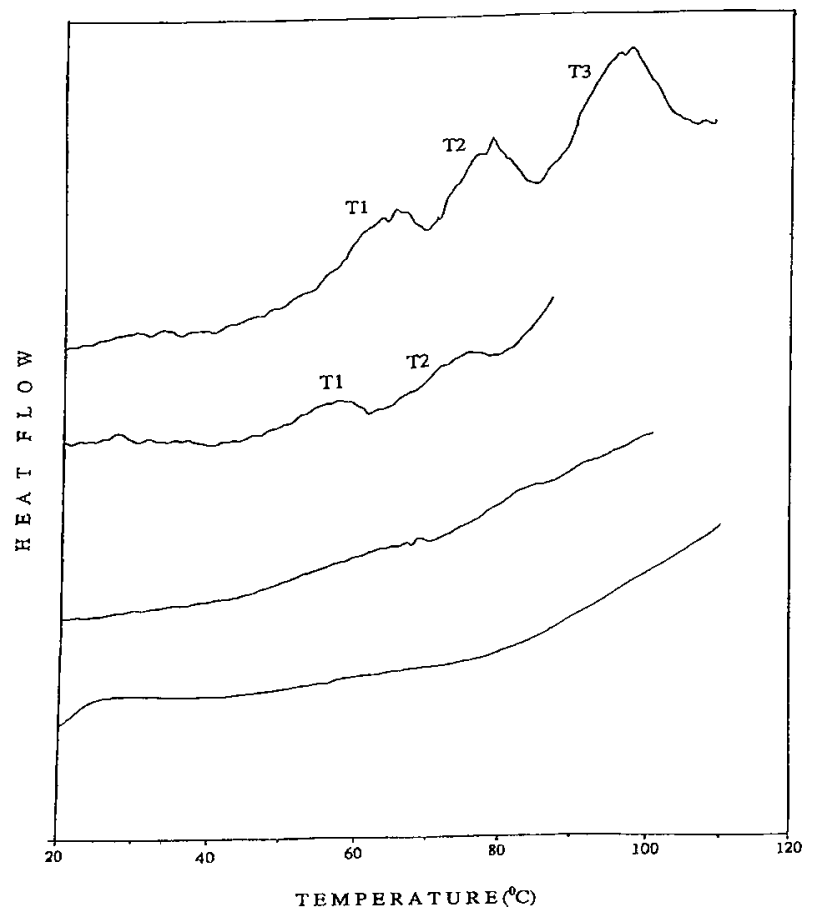

Fig. 4. DSC Thermograms of SC Untreated and Treated with $12 \mathrm{ml}$ of $50 \% \mathrm{v} / \mathrm{v}$ Ethanol with or without $5 \% \mathrm{w} / \mathrm{v}$ Terpenes for $48 \mathrm{~h}$

Top to bottom; untreated SC hydrated to $20-25 \%$, SC treated with $50 \% \mathrm{v} / \mathrm{v}$ ethanol, limonene oxide $/ 50 \% \mathrm{v} / \mathrm{v}$ ethanol and pinene oxide $/ 50 \% \mathrm{v} / \mathrm{v}$ ethanol.

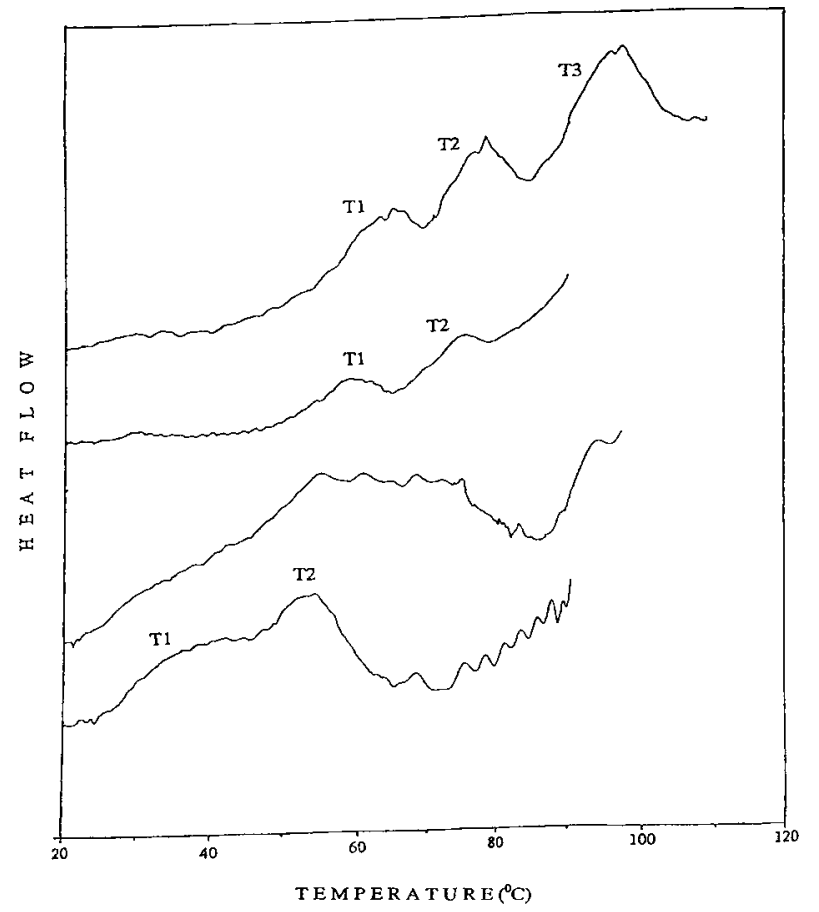

Fig. 5. DSC Thermograms of SC Untreated and Treated with $7 \mathrm{ml}$ of $50 \%$ $\mathrm{v} / \mathrm{v}$ Ethanol with or without $5 \% \mathrm{w} / \mathrm{v}$ Terpenes for $12 \mathrm{~h}$

Top to bottom; untreated SC hydrated to $20-25 \%$, SC treated with $50 \% \mathrm{v} / \mathrm{v}$ ethanol, limonene oxide $/ 50 \% \mathrm{v} / \mathrm{v}$ ethanol and pinene oxide $/ 50 \% \mathrm{v} / \mathrm{v}$ ethanol.

ethanol was the effective solvent system to enhance the permeation of HP. The terpenes in both solvents provided relative solubility parameter $(\mathrm{Cr})$ values above one. Since the $\mathrm{Cr}$ values are higher for $50 \% \mathrm{v} / \mathrm{v}$ ethanol than for $100 \% \mathrm{v} / \mathrm{v} \mathrm{PG}$,

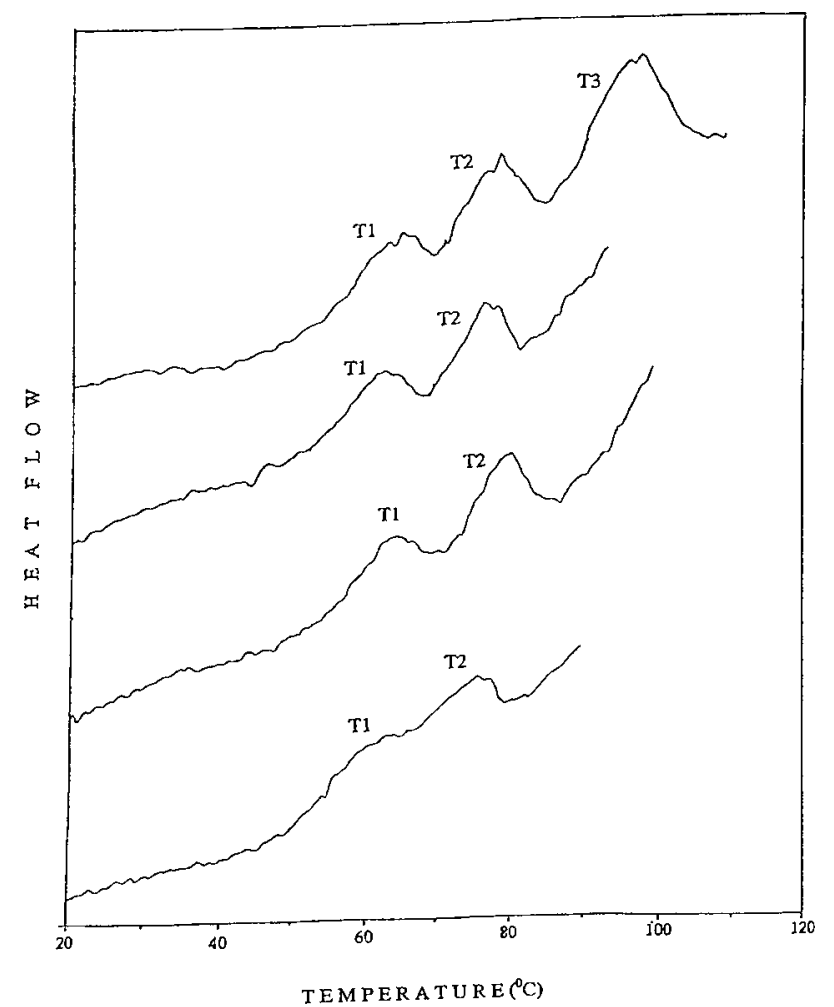

Fig. 6. DSC Thermograms of SC Untreated and Treated with $12 \mathrm{ml}$ of Propylene Glycol with or without 5\% w/v Terpenes for $48 \mathrm{~h}$

Top to bottom; untreated SC hydrated to $20-25 \%$, SC treated with propylene glycol, limonene oxide $/ 100 \% \mathrm{v} / \mathrm{v}$ PG and pinene oxide $/ 100 \% \mathrm{v} / \mathrm{v}$ PG.

terpenes in $50 \% \mathrm{v} / \mathrm{v}$ ethanol showed a greater effect on the solubility of HP. Permeation enhancement also depends on the chemical potential of the drug in the vehicle. Although terpenes provided $\mathrm{Cr}$ values greater than one, as saturated drug solutions were used for diffusion studies, the chemical potential of the drug was at maximum and equal in all the solvent systems.

For the oral dose of $3-10 \mathrm{mg}$ per day, the steady state plasma concentration of HP would be in the range of 0.8 $5.15 \mathrm{ng} / \mathrm{ml} .{ }^{16,27)}$ As per Eq. 9, the therapeutic transdermal daily dose $(T d)$ is $1.8-6 \mathrm{mg}$ for the same oral dose. Since HP permeation from $50 \% \mathrm{v} / \mathrm{v}$ ethanol and $100 \% \mathrm{v} / \mathrm{v}$ PG without enhancers provided only sub-therapeutic plasma levels and sub-therapeutic daily-permeated doses, enhancers are required to increase HP permeation (Table 3). Although terpenes in both solvents enhanced the HP permeation, only terpenes in $50 \% \mathrm{v} / \mathrm{v}$ ethanol provided sufficient therapeutic plasma concentration and permeated daily amount. Terpenes in $100 \% \mathrm{v} / \mathrm{v}$ PG enhanced HP permeation only to sub-therapeutic levels. The limonene oxide in $50 \% \mathrm{v} / \mathrm{v}$ ethanol system could give dose and formulation flexibility because it increased plasma concentration and daily permeated amount of HP above the upper limit of its therapeutic range.

Terpenes in both solvents did not increase the solubility of HP in SC lipids from that of the controls as their partition coefficients were not greater than those of the controls (Table 4). The lower partition values with terpene solutions compared to the controls could be due to the lower chemical potential of the drug in terpene solutions than in the controls as the drug concentration used was the same and sub-saturated in both control and terpene solutions. The chemical potential 
of a solute in a solution increases with its concentration and reaches to a maximum at saturation. Since saturated solubilities of HP in terpene solutions are higher than that of the controls (Table 1), the chemical potential of the drug was lower in terpene solutions at the same drug concentrations compared to controls, therefore, the lower leaving tendency resulted in a lower partition coefficient value.

The thermograms of SC treated with $50 \% \mathrm{v} / \mathrm{v}$ ethanol for $48 \mathrm{~h}$ showed reductions in T1 and T2 peak areas (Fig. 4). Absence of these endotherms after a $48 \mathrm{~h}$ treatment with the terpenes in $50 \% \mathrm{v} / \mathrm{v}$ ethanol was possibly due to a decrease in peak areas of these transitions to the baseline. The peak area reduction could be due to either the fluidisation of the lipids at the experimental temperature $\left(21 \pm 1^{\circ} \mathrm{C}\right)$ or the extraction of lipids. ${ }^{28)}$ The IR spectra of SC treated with $50 \% \mathrm{v} / \mathrm{v}$ ethanol and terpenes in $50 \% \mathrm{v} / \mathrm{v}$ ethanol showed decreases in peak heights and areas of $\mathrm{CH}_{2}$ stretchings (Table 5, Fig. 3) but these peaks did not either shift to higher frequencies or their peak widths increased, indicating that $50 \% \mathrm{v} / \mathrm{v}$ ethanol and terpenes in $50 \% \mathrm{v} / \mathrm{v}$ ethanol extracted the lipids, but did not fluidise the lipids. Limonene oxide in $50 \% \mathrm{v} / \mathrm{v}$ ethanol extracted the largest amount of lipids followed by pinene oxide in $50 \% \mathrm{v} / \mathrm{v}$ ethanol and $50 \% \mathrm{v} / \mathrm{v}$ ethanol alone. Only $15-20 \%$ lipids were extracted after a $48 \mathrm{~h}$ treatment with terpenes in $50 \% \mathrm{v} / \mathrm{v}$ ethanol. This might not have led to the complete absence of $\mathrm{T} 1$ and $\mathrm{T} 2$ endotherms. The broadening of these peaks due to a decrease in cooperativities of $\mathrm{T} 1$ and $\mathrm{T} 2$ could explain the absence of these peaks. A decrease in cooperativity indicates a disruption of the lipid bilayer. ${ }^{21)} \mathrm{Al}-$ though lipid endotherms were not observed in the first heating run, probably the second run could have shown the presence of the lipids as the second run of untreated SC was reported to show a single lipid endotherm with larger peak area than the T1 and T2 peak areas of the first run. Leopold et $a l .{ }^{28)}$ reported the presence of a considerable amount of lipids in the SC after treatment with lipophilic vehicles. This was shown from the presence of lipid endotherm in the second heating run, although there was a complete disappearance of lipid endotherms during the first run.

The decrease in Tm of lipid transitions in the thermograms of SC treated with $50 \% \mathrm{v} / \mathrm{v}$ ethanol and pinene oxide in $50 \%$ $\mathrm{v} / \mathrm{v}$ ethanol for $12 \mathrm{~h}$ (Fig. 5) could be due to the melting point depression of SC lipids, which was reported with oleic acid and other terpenes. ${ }^{25,26)}$ Since Tm1 was depressed to around $36^{\circ} \mathrm{C}$ by pinene oxide and the onset temperature of this lipid transition was approximately $29^{\circ} \mathrm{C}$, the $\mathrm{T} 1$ lipid subset, would partially be in a fluid state at the physiological temperature $\left(\mathrm{ca} .32^{\circ} \mathrm{C}\right)$ of the skin, thereby facilitating the higher permeation of HP. Yamane et al. $^{21)}$ reported that a decrease in Tm was similar in spite of increasing the terpene treatment time from 1 to $6 \mathrm{~h}$ and $8 \mathrm{~h}$. So Tm1 and onset temperature of $\mathrm{T} 1$ endotherm would be approximately at $36^{\circ} \mathrm{C}$ and $29^{\circ} \mathrm{C}$, respectively after a $48 \mathrm{~h}$ pinene oxide treatment and this should result in a shift of $\mathrm{CH}_{2}$ stretching bands in IR spectrum to a higher wavenumber and an increase in their peak widths due to the fluidisation of lipids. But no change in peak frequency or peak width was observed and this could be due to the low temperature at which the IR experiment was conducted $\left(21 \pm 1{ }^{\circ} \mathrm{C}\right.$, less than physiological temperature). Pinene oxide decreased the cooperativity of $\mathrm{T} 1$, which was due to the disruption of the lipid bilayer at this lipid subset.
Limonene oxide in $50 \% \mathrm{v} / \mathrm{v}$ ethanol after a $12 \mathrm{~h}$ treatment produced a single large endotherm, which could be due to the coalescence of $\mathrm{T} 1$ and $\mathrm{T} 2$ endotherms. Limonene oxide probably disrupted lipid bilayer that resulted in the broadening of $\mathrm{T} 1$ and $\mathrm{T} 2$ peaks and therefore led to their coalescence. Cornwell et al. ${ }^{25}$ ) also reported that nerolidol broadened and coalesced T1 and T2 endotherms and attributed it to the disruption of lipid bilayer. Since this single large endotherm reached the baseline at around $80^{\circ} \mathrm{C}$, limonene oxide decreased $\mathrm{Tm} 2$ as the untreated $\mathrm{SC}$ showed $\mathrm{Tm} 2$ at approximately $79^{\circ} \mathrm{C}$. The effect of limonene oxide on $\mathrm{Tm} 1$ could not be observed properly due to the coalescence of $\mathrm{T} 1$ and $\mathrm{T} 2$.

The IR spectra of SC treated with $100 \% \mathrm{v} / \mathrm{v}$ PG with or without terpenes decreased the heights and areas of $\mathrm{CH}_{2}$ stretchings, indicating that lipids were extracted from $\mathrm{SC}$ (Table 6, Fig. 3). Since 100\% v/v PG and terpenes in $100 \%$ v/v PG extracted lipids similarly, the lipid extraction could be primarily caused by $100 \% \mathrm{v} / \mathrm{v}$ PG. PG (100\% v/v) and limonene oxide in $100 \% \mathrm{v} / \mathrm{v}$ PG did not fluidise lipids as the lipid peak frequencies and peak widths were not increased. Pinene oxide, did not introduce gauche conformers along acyl chains as there was no shift in the frequency of the lipid peaks. It, however, enhanced lipid fluidity by increasing the rates and amplitudes of the translational and rotational motions of individual $\mathrm{CH}_{2}$ groups and acyl chains as bandwidths were slightly increased.

In the thermogram of SC treated with $100 \% \mathrm{v} / \mathrm{v}$ PG for $48 \mathrm{~h}$, a minimal difference in enthalpies or cooperativities of T1 and T2 was observed compared to the untreated SC (Fig. 6). The same observation was reported earlier with $100 \% \mathrm{v} / \mathrm{V}$ $\mathrm{PG}^{25}$ and it was also reported that $100 \% \mathrm{v} / \mathrm{v} \mathrm{PG}$ did not decrease lipid bilayer reflections of $\mathrm{SC}$ in small angle X-ray diffraction $^{8)}$ and these observations were attributed to the disruption of lipid bilayers whilst leaving overall bilayer structure intact. The thermogram of SC treated with pinene oxide in $100 \% \mathrm{v} / \mathrm{v}$ PG for $48 \mathrm{~h}$ showed a decrease in the peak areas of T1 and T2. Since lipids were not extracted by pinene oxide as shown in IR spectrum, a decrease in lipid endotherms was due to the fluidisation of lipids, which was in agreement with the increase in band widths of $\mathrm{CH}_{2}$ stretchings in the IR studies. A decrease in the peak widths of $\mathrm{CH}_{2}$ stretchings was observed in IR spectra of SC treated with $50 \% \mathrm{v} / \mathrm{v}$ ethanol, $100 \% \mathrm{v} / \mathrm{v} \mathrm{PG}$ and terpenes in $50 \% \mathrm{v} / \mathrm{v}$ ethanol and $100 \% \mathrm{v} / \mathrm{v}$ PG except pinene oxide in $100 \% \mathrm{v} / \mathrm{v}$ PG (Tables 5, 6). In the absence of lipid fluidity in all these cases, the decrease in peak heights and areas probably reduced the peak widths.

Limonene oxide in $100 \% \mathrm{v} / \mathrm{v}$ PG increased the cooperativities of lipid endotherms, which could be due to an increase in lipid bilayer cohesion. ${ }^{21)}$ An increase in bilayer cohesion is possible with oxide terpenes, which can align within the lipid bilayer and form hydrogen bonds with the polar head group of SC lipids. ${ }^{29,30)}$ So limonene oxide possibly disrupted the bilayer by aligning within hydrocarbon chains and by forming bonds with polar head group of lipids, whilst leaving the overall bilayer structure intact or enhancing its periodicity. Pinene oxide, despite capable of forming hydrogen bonds, did not increase the cooperativities of lipid endotherms. This difference in action between two oxide terpenes in $100 \% \mathrm{v} / \mathrm{V}$ PG could be attributed to their molecular orientations. 
Limonene oxide is a monocyclic terpene whereas pinene oxide is a bicyclic terpene (oxide ring is not counted) (Fig. 1). Therefore, the insertion of limonene oxide between hydrocarbon chains would be easier than pinene oxide due to its less bulky structure than the latter. Cornwell et al. ${ }^{30)}$ reported that the monocyclic sesquiterpenes increased the permeation of 5-flurouracil more than highly bunched cyclic sesquiterpenes, attributing it to molecular orientations within the lipid bilayer. Since 100\% v/v PG and terpenes in 100\% v/v PG decreased Tm of lipid endotherms similarly and this decrease was not much lower than the Tm values of untreated SC, the m.p. depression of lipids might not have an effect on the permeation enhancement of HP. Ethanol $(50 \% \mathrm{v} / \mathrm{v})$ and terpenes in $50 \% \mathrm{v} / \mathrm{v}$ ethanol after the $12 \mathrm{~h}$ and $48 \mathrm{~h}$ treatments and $100 \% \mathrm{v} / \mathrm{v}$ PG and terpenes in $100 \% \mathrm{v} / \mathrm{v}$ PG after a $48 \mathrm{~h}$ treatment removed protein endotherm probably by dehydrating the SC.

The interaction of terpenes with SC differed in $50 \% \mathrm{v} / \mathrm{v}$ ethanol and $100 \% \mathrm{v} / \mathrm{v}$ PG, although these terpenes in both solvents enhanced the permeation of HP. The two terpenes in $50 \% \mathrm{v} / \mathrm{v}$ ethanol showed similar mechanisms, but showed different mechanisms in $100 \% \mathrm{v} / \mathrm{v}$ PG. Terpenes in $50 \% \mathrm{v} / \mathrm{v}$ ethanol extracted lipids and disrupted the lipid bilayer packing. But these modes of action did not appear to be the major mechanisms of enhancement in 100\% v/v PG. Limonene oxide in $100 \% \mathrm{v} / \mathrm{v}$ PG disrupted lipid bilayer probably by aligning within hydrocarbon chains, whilst leaving overall bilayer structure intact whereas pinene oxide in $100 \% \mathrm{v} / \mathrm{v} \mathrm{PG}$ fluidised lipids by increasing the movement of $\mathrm{CH}_{2}$ groups and acyl chains within the ordered environment.

Although terpenes in both solvents enhanced permeation of HP by various mechanisms, they also increased lag time (Table 1), which could possibly be due to a gradual increase in SC permeability. Cornwell et al. $^{30)}$ reported that some sesquiterpenes increased the lag time despite increasing the permeation of 5-fluorouaracil and this was attributed to the gradual increase in membrane permeability produced by the slow redistribution of the enhancers within the SC and consequently a conditioning of the membrane in the early stages of the diffusion process.

In conclusion, the interaction of enhancer with $\mathrm{SC}$ varied in $50 \% \mathrm{v} / \mathrm{v}$ ethanol and $100 \% \mathrm{v} / \mathrm{v}$ PG. Structurally similar enhancers may have similar or different modes of action depending upon the solvent system. Both terpenes showed a similar action in $50 \% \mathrm{v} / \mathrm{v}$ ethanol but different actions in $100 \% \mathrm{v} / \mathrm{v}$ PG. However, these terpenes in $50 \% \mathrm{v} / \mathrm{v}$ ethanol or $100 \% \mathrm{v} / \mathrm{v}$ PG did not increase the partition of the drug into SC and limonene oxide showed higher enhancement activity than pinene oxide in $50 \% \mathrm{v} / \mathrm{v}$ ethanol or $100 \% \mathrm{v} / \mathrm{v}$ PG. Although the terpenes enhanced permeation of HP in both these solvents, $50 \% \mathrm{v} / \mathrm{v}$ ethanol appeared to be the more suitable vehicle as terpenes in $50 \% \mathrm{v} / \mathrm{v}$ ethanol was predicted to deliver HP at the desired therapeutic plasma concentration and therapeutic permeated daily doses.

\section{REFERENCES}

1) Godwin D. A., Michniak B. B., Drug Dev. Ind. Pharm., 25, 905-915 (1999).

2) Williams A. C., Barry B. W., Pharm. Res., 8, 17-24 (1991).

3) Obata Y., Takayama K., Machida Y., Nagai T., Drug Design \& Discovery, 8, 137-144 (1991).

4) Gao S., Singh J., J. Control. Release., 51, 193-199 (1998).

5) Levang A. K., Zhao K., Singh J., Int. J. Pharmaceut., 181, 255-263 (1999).

6) Chattaraj S. C., Walker R. B., "Percutaneous Penetration Enhancers," ed. by Smith E. W., Maibach H. I., CRC Press, New York, 1995, pp. $5-15$.

7) Levison K. K., Takayama K., Isowa K., Okabe K., Nagai T., J. Pharm. Sci., 83, 1367-1372 (1994).

8) Cornwell P. A., Barry B. W., Stoddart C. P., Bouwstra J. A., J. Pharm. Pharmacol., 46, 938-950 (1994).

9) Naik A., Guy R. H., "Mechanisms of Transdermal Drug Delivery," ed. by Potts R. O., Guy R. H., Marcel Dekker, New York, 1997, pp. 87149.

10) Vaddi H. K., Wang L. Z., Ho P. C., Chan S. Y., Int. J. Pharmaceut., 212, 247-255 (2001)

11) Vaddi H. K., Wang L. Z., Ho P. C., Chan Y. W., Chan S. Y., Chem. Pharm. Bull., 49, 1395-1400 (2001).

12) Megrab N. A., Williams A. C., Barry B. W., Int. J. Pharmaceut., 116, 101-112 (1995).

13) Kligman A. M., Christophers E., Arch. Dermatol., 88, 702-705 (1963).

14) Wester R. C., Maibach H. I., Sedik L., Melendres J., Fundam. Appl. Toxicol., 19, 1-5 (1992).

15) Okamato H., Komatsu H., Hashida M., Sezaki H., Int. J. Pharmaceut., 30, 35-45 (1986).

16) Almirall M., Montana J., Escribano E., Obach R., Berrozpe J. D., Drug Res., 46, 676-680 (1996).

17) Forsman A., Ohman R., Curr. Ther. Res., 20, 319-336 (1976)

18) Reynolds J. E. F., "Martindale The Extra Pharmacopoeia," 31st ed., The Pharmaceutical Press, London, 1996, pp. 714-715.

19) Lewis R. N. A. H., Mc Eelhaney R. N., "Infrared Spectroscopy of Biomolecules," ed. by Mantsch H. H., Chapman D., Wiley-Liss, New York, 1996, pp. 159-202.

20) Harrison J. E., Groundwater P. W., Brain K. R., Hadgraft J., J. Control. Release, 41, 283-290 (1996).

21) Yamane M. A., Williams A. C., Barry B. W., Int. J. Pharmaceut., 116, 237-251 (1995).

22) Cornwell P. A., Barry B. W., Int. J. Pharmaceut., 94, 189-194 (1993).

23) Barry B. W., J. Control. Release, 6, 85-97 (1987).

24) Golden G. M., Guzek D. B., Harris R. R., McKie J. E., Potts R. O., J. Invest. Dermatol., 86, 255-259 (1986).

25) Cornwell P. A., Barry B. W., Bouwstra J. A., Gooris G., Int. J. Pharmaceut., 127, 19-26 (1996).

26) Francoeur M. L., Golden G. M., Potts R. O., Pharm. Res., 7, 621-627 (1990).

27) Cuyper H. D., Bollen J., Praag H. M. V., Verstraeten D., Br. J. Psychiatry., 148, 560-566 (1986).

28) Leopold C. S., Lippold B. C., J. Pharm. Pharmacol., 47, 276-281 (1995).

29) Moghimi H. R., Williams A. C., Barry B. W., J. Pharm. Pharmacol., 50, 955-960 (1998).

30) Cornwell P. A., Barry B. W., J. Pharm. Pharmacol., 46, 261-269 (1994). 